\title{
Proximate compositions, phytochemical constituents, antioxidant activities and phenolic contents of seed and leaves extracts of Egyptian leek (Allium ampeloprasum var. kurrat)
}

\author{
Fouad Abd El-Rehem Ahmed Abd El-Rehem and Rehab Farouk Mohammed Ali *
}

Department of Biochemistry, Faculty of Agriculture, Cairo University, 12613, Giza, Egypt

${ }^{*}$ Corresponding author at: Department of Biochemistry, Faculty of Agriculture, Cairo University, 12613, Giza, Egypt. Tel.: +2.0128.2959994; fax: +2.023.7742600.E-mail address: malkanany@yahoo.com (R.F.M. Ali).

\section{ARTICLE INFORMATION}

Received: 24 November 2012

Received in revised form: 14 March 2013

Accepted: 25 March 2013

Online: 30 September 2013

\section{KEYWORDS}

Leek

Leaf

Leaf

Antioxidant activities

2,2-Diphenyl-1-picrylhydrazy

Allium ampeloprasum var. kurrat

\begin{abstract}
Leeks (Allium ampeloprasum var. kurrat.) are the most commercially produced vegetables in the world. The seed and leaves of this plant were analyzed for proximate composition and mineral content. Phytochemical screening, total polyphenols, total flavonoids, tannins, radical scavenging activity by 2,2-diphenyl-1-picrylhydrazyl (DPPH), total antioxidant activities and phenolic profile of various extracts of Egyptian leek were screened and investigated. The seed is good source of fat and protein, whereas the leaves are good source of crude fiber and ash. Both seed and leaves contain substantial quantities of potassium, calcium, and phosphorus. Methanolic and ethanolic extracts of seeds and leaves were found to contain alkaloids, steroids, terpenoids, flavonoids, tannins, saponines, reducing sugars, proteins and oil. The highest values of total phenolic, flavonoid, tannin, radical scavenging and antioxidant activities were observed for methanolic and ethanolic extracts of seed and leaves. HPLC analysis results showed that certain phenolic compounds; gallic, coumaric, caffeic, tannic, vanillic, chlorogenic, kaempferol, and quercetin exist in methanolic extracts of both seed and leaves at different levels. These results suggested that Allium ampeloprasum phenolic compounds could be used as a natural antioxidant.
\end{abstract}

\section{Introduction}

Phytochemicals, naturally occurring components found in plants, have a wide range of biological effects, including antiinflammatory, antimicrobial and antioxidant activities [1]. This is often attributed to the different antioxidant components in fruits and vegetables, such as ascorbic acid, vitamin E, carotenoids, lycopene, polyphenols, and other phytochemicals [2]. Leafy vegetables are a valuable part of the diet owing to their nutritive values, which plays an important role in the human diet [3]. In recent years, there has been a great interest in finding natural antioxidants from plant materials to replace synthetic antioxidants, which are being restricted due to their carcinogenicity [4]. Several crude extracts and pure natural compounds from plants have been reported to have antioxidant and radical scavenging activities [5]. Recovery of antioxidant compounds from plant materials is typically accomplished through different extraction techniques taking into account their chemistry and uneven distribution in the plant matrix [6]. Solvent extraction is the most frequently used technique for isolation of plant antioxidant compounds [7]. Methanol and ethanol have been extensively used to extract antioxidant compounds from various plants and plant-based foods (fruits, vegetables etc.) such as plum, strawberry, pomegranate, broccoli, rosemary, sage, sumac, rice bran, wheat grain and bran, mango seed kernel, citrus peel, and many other fruit peels [8]. Various antioxidant activity methods have been used to evaluate the antioxidant activity of phenolics such as active oxygen sepsis (superoxide anion, peroxyl radical and hydroxyl radical), 1,1-diphenyl-2-picrylhydraxyl (DPPH) radical and 2,2- azino-bis(3-ethyl benzothiazoline)-6-sulfonate radical cation (ABTS). These methods are widely used to analyze the capacity of free radical scavenging activity of the phenolic components [9].

The Allium group is one of the world's most widely cultivated vegetable groups, with their culinary and medicinal uses. The Allium genus includes approximately 500 species, the most widely used of which are onions, garlic, and leeks [10]. Equally varied are their health benefits, because they contain a range of phytochemicals with an array of biological effects. Evidence showed that they play an important role in protecting against major lifestyle chronic diseases as well as health problems associated with ageing. Their antimicrobial activity, long recognized in folk remedies, has also now been scientifically validated.

Leeks (Allium ampeloprasum L.) are the most commercially produced vegetables in the world. Along with onions and garlic, leeks belong to the Allium genus (family Alliaceae). Fresh leeks are a good source of nitrates, flavonoids, polysaccharides and glucosinolates in addition to numerous organosulfur components contributing to their rich flavor [11]. Epidemiological and laboratory studies have suggested that Allium vegetables have tumor-inhibitory properties. The consumption of leeks reduces risk of prostate, colorectal, stomach and breast cancer [12]. The anti-carcinogenic action may be related to the high content of organosulfur compounds and other biophenols with high antioxidant activity [13]. These bioactive compounds also have antifungal activity [14] and inhibitory activity on human platelet aggregation, which can prevent atherosclerosis [15]. Kurrat (Allium ampeloprasum var. kurrat), previously named 
Allium Kurrat Schweinfurth. Ex Krause [16], looks like leek but is much smaller. Kurrat is popular vegetable in Egypt and eastern Mediterranean countries where it is mainly used fresh and seasoning [17]. Kurrat is completely inter fertile with leek [18] and was reported to be resistant to yellow stripe virus which causes significant damage to leek [19].

The present study was carried out to determine the proximate and mineral compositions of the seeds and leaves of Egyptian leek. Moreover, the phytochemical contents (i.e., polyphenols, flavonoids, Tannins), antioxidant and free radical scavenging activity measured by DPPH and $\beta$-carotene bleaching assays and phenolic profiles of extracts of seeds and leaves of Egyptian leek (Allium ampeloprasum var. kurrat) were investigated and evaluated.

\section{Experimental}

\subsection{Chemical reagents}

Folin-Ciocalteu reagent, 2,2-diphenyl-1-picrylhydrazyl (DPPH), 2,4,6-tri(2-pyridyl)-s-triazine (TPTZ), sodium carbonate, aluminum chloride and $\beta$-carotene were purchased from Sigma Chemical Co., Ltd (St. Louis, MO, USA). Pure hexane, chloroform, ethanol, acetone, petroleum ether and methanol were purchased from E. Merck Co. (Darmstadt, Germany), and distilled before use. All other reagents were of analytical grade.

\subsection{Collection of plant material}

Egyptian leek (Allium ampeloprasum var. kurrat) seeds and leaves were collected from special farm at Menoufia governorate, Egypt, in September, 2012.

\subsection{Determination of chemical composition and mineral contents of the seed and leaves of Egyptian leek (Allium ampeloprasum var. kurrat.)}

Moisture, crude oil, crude protein ( $\mathrm{N} \times \mathrm{6.25}$ ) and total ash of samples were determined as described in A.O.A.C [20]. The minerals, i.e., $\mathrm{Ca}, \mathrm{Fe}, \mathrm{Zn}, \mathrm{K}, \mathrm{Cu}, \mathrm{Mn}, \mathrm{Mg}$ and $\mathrm{Na}$ were determined in a dilute solution of the ashed samples by atomic absorption spectrophotometer (3300 Perkin-Elmer) as described in A.O.A.C [20].

\subsection{Preparation of extracts}

Egyptian leek (Allium ampeloprasum var. kurrat) seeds and leaves were dried at $38{ }^{\circ} \mathrm{C}$ for $48 \mathrm{~h}$ in an air convection oven until the powder did not form lumps when touched and then ground and passed through a $150 \mu \mathrm{m}$ mesh sieve. Dried material $(200 \mathrm{~g})$ was separately extracted with $2000 \mathrm{~mL}$ of different solvents methanol, ethanol, hexane, petroleum ether, chloroform and deionized water by maceration at room temperature for $72 \mathrm{~h}$. The extract was filtered using filter paper (Whatman no. 1). Extraction and filtration are repeated until the residue is colorless. Extractions were carried out by triplicates. The solvent was removed under vacuum at $45{ }^{\circ} \mathrm{C}$ using a rotary evaporator (Laborota 4000-efficient, Heildolph, Germany). The obtained extracts were kept in light-protected containers at $-18^{\circ} \mathrm{C}$ until further use.

\subsection{Yield measurement}

The extraction yield $(\%, w / w)$ from all the dried extracts was measured by equation (1).

Yield $(\%)=\left(\mathrm{W}_{1} / \mathrm{W}_{2} \times 100\right)$

where $\mathrm{W}_{1}$ is the weight of the extract after solvent evaporation and $W_{2}$ is the weight of the plant powder.

\subsection{Preliminary Phytochemical screening}

Phytochemical screening of various extracts of seeds and leaves of Egyptian leek (Allium ampeloprasum var. kurrat) was carried out using standard phytochemical methods as described by Trease and Evans [21].

\subsection{Antioxidant components estimation}

\subsubsection{Determination of total polyphenols}

Total polyphenols were determined according to the method of [22]. An aliquot from extract $(0.1 \mathrm{~mL})$ was dissolved in a $10 \mathrm{~mL}$ mixture of acetone and water $(6: 4, v: v)$. Sample $(0.2$ $\mathrm{mL}$ ) was mixed with $1.0 \mathrm{~mL}$ of ten-fold diluted Folin-Ciocalteu reagent and $0.8 \mathrm{~mL}$ of $75 \mathrm{~g} / \mathrm{L}$ sodium carbonate solution. After standing for $30 \mathrm{~min}$ at room temperature, the absorbance was measured at $725 \mathrm{~nm}$. Phenolic contents were calculated on the basis of the standard curve for gallic acid (GAL). The results were expressed as $\mathrm{mg}$ of gallic acid equivalent per $100 \mathrm{~g}$ dry weight (DW).

\subsubsection{Determination of total flavonoids}

The total flavonoid content was determined using the Dowd method [23]. $5 \mathrm{~mL}$ of $2 \%$ Aluminum trichloride in methanol was mixed with the same volume of the extract solution $(0.4 \mathrm{mg} / \mathrm{mL})$. Absorbance readings at $415 \mathrm{~nm}$ were taken after $10 \mathrm{~min}$ against a blank sample consisting of a $5 \mathrm{~mL}$ extract with $5 \mathrm{~mL}$ methanol without $\mathrm{AlCl}_{3}$. The total flavonoid content was determined using a standard curve with catechin $(0-100 \mathrm{mg} / \mathrm{L})$ as the standard. Total flavonoid content is expressed as mg of catechin equivalents (CE) /100 g DW.

\subsubsection{Total tannins determination}

The total tannin content in the extracts was determined by modified method of Polshettiwar et al. [24]. The sample (0.1 $\mathrm{mL}$ ) was mixed with $0.5 \mathrm{~mL}$ of Folin-Denis reagent followed by $1 \mathrm{~mL}$ of $\mathrm{Na}_{2} \mathrm{CO}_{3}(0.5 \%, w: v)$ solution and distilled water (up to 5 $\mathrm{mL}$ ). The absorbance was measured at $755 \mathrm{~nm}$ within $30 \mathrm{~min}$ of the reaction against the blank. The total tannin in the extract was expressed as the equivalent to tannic acid (mg TE/100g DW).

\subsection{Analysis of phenolic compounds using HPLC}

Phenolic compounds of methanolic extract of the seeds and leaves of Egyptian leek were identified using a method introduced by $\mathrm{Wu}$ et al. [25]. The Waters HPLC system equipped with automated gradient controller, 510 pumps, U6K injector, 481 detector, 746 data module and Waters $\mu$ bondapak C18 column (3.9 × $300 \mathrm{~mm})$, was used for the analysis. Samples and mobile phases were filtrated through a $0.45 \mathrm{~mm}$ Millipore filter, type GV (Millipore, Bedford, MA) prior to HPLC injection. Elution was carried out at ambient temperature between 24 to $28{ }^{\circ} \mathrm{C}$ using water:methanol:acetic acid $(70.0: 29.5: 0.5, v: v: v)$ as a mobile phase at a flow rate 1.0 $\mathrm{mL} / \mathrm{min}$. Each sample was analyzed in triplicate. The UV detection was carried out at $280 \mathrm{~nm}$. Linear calibration curves for standards (peak area vs. concentration) were constructed with $r^{2}$ exceeding 0.999 . The identified phenolic compounds were quantified on the basis of their peak area and compared with calibration curves obtained with the corresponding standards and then expressed as $\mathrm{mg} / 100 \mathrm{~g}$ of extract.

\subsection{Determination of antioxidant efficiency}

\subsubsection{Free radical scavenging capacity}


The free radical scavenging capacity of various solvent extracts of seeds and leaves of Egyptian leek was analyzed by using 1,1-diphenyl-2-picrilhydrazyl (DPPH) assay [26]. Aliquot $(100 \mu \mathrm{L})$ of extract was mixed with $5 \mathrm{~mL}$ of $6 \times 10^{-3} \mathrm{M}$ methanolic solution of DPPH radical. The mixture was shaken vigorously and left to stand for $30 \mathrm{~min}$ in the dark. The absorbance was then measured at $517 \mathrm{~nm}$ against a blank. The control was prepared, as above, without any extract and methanol was used for the base line correction. The radicalscavenging activity was expressed as percentage of inhibition and calculated using the equation (2).

$\%$ Radical scavenging activity $=[($ Abs control - Abs test $) /($ Abs control $)] \times 100$.

where Abs control is the absorbance of DPPH radical + methanol; Abs test is the absorbance of DPPH radical + sample extract/standard.

\subsection{2. $\beta$-Carotene bleaching assay}

The antioxidant activity of extracts of Egyptian leek was determined by using $\beta$-carotene bleaching method, according to the method described by reference [22]. One $\mathrm{mL}$ of $\beta$ carotene solution ( $0.2 \mathrm{mg} \beta$-carotene/ $\mathrm{mL}$ of chloroform) was transferred into a round-bottom flask containing $0.02 \mathrm{~mL}$ of linoleic acid and $0.2 \mathrm{~mL}$ of Tween 20. The chloroform was evaporated at $40{ }^{\circ} \mathrm{C}$ using rotary evaporator. The resultant mixture was immediately diluted with $100 \mathrm{~mL}$ of deionized water and mixed for 2 min to form emulsion. A mixture prepared similarly without $\beta$-carotene was used as a blank. A control, containing $0.2 \mathrm{~mL}$ of $70 \%$ ethanol instead of extract was also prepared. Five $\mathrm{mL}$ of the emulsion was transferred into test tube containing $0.2 \mathrm{~mL}$ of extract. The tubes were placed at $50{ }^{\circ} \mathrm{C}$ in water bath for $2 \mathrm{hr}$. The absorbance was recorded at $470 \mathrm{~nm}$ using UV-Visible spectrophotometer (Shimadzu, Kyoto, Japan). The percentage antioxidant activity was calculated based on the equation (3).

Antioxidant activity $(\%)=\frac{1-(\mathrm{A} 0 \text { at } 470-\mathrm{At} \text { at } 470)}{\left(\mathrm{A}^{\circ} 0 \text { at } 470-\mathrm{A}^{\circ} \mathrm{t} \text { at } 470\right)} \times 100$

where $\mathrm{A} 0$ and $\mathrm{A}^{\circ} 0$ are the absorbance values measured at zero time of incubation for extracts and control, respectively. At and $\mathrm{A}^{\circ} \mathrm{t}$ are the absorbance values for extracts and control measured at $\mathrm{t}=120 \mathrm{~min}$

\subsubsection{Ferric reducing antioxidant power (FRAP) assay}

The FRAP assay was carried out according to the method introduced by $\mathrm{Xu}$ and Chang [27], with some modification. Briefly, the FRAP reagent was prepared from a sodium acetate buffer $(0.3 \mathrm{~mol} / \mathrm{L}, \mathrm{pH}=3.6), 10 \mathrm{mmol} / \mathrm{L}$ TPTZ solution in 40 $\mathrm{mmol} / \mathrm{L} \mathrm{HCl}$ and $20 \mathrm{mmol} / \mathrm{L} \mathrm{FeCl}_{3}$ solution in volume proportions of 10:1:1 ( $v: v: v)$, respectively. An aliquot of $200 \mu \mathrm{L}$ of an extract was mixed with $3 \mathrm{~mL}$ of FRAP reagent $(10$ parts of $300 \mathrm{mM}$ sodium acetate buffer at $\mathrm{pH}=3.6$, one part of $10 \mathrm{mM}$ TPTZ solution and one part of $20 \mathrm{mM} \mathrm{FeCl} 3.6 \mathrm{H}_{2} \mathrm{O}$ solution) and the reaction mixture was incubated in a water bath at $37{ }^{\circ} \mathrm{C}$. The increase in absorbance at $593 \mathrm{~nm}$ was measured after 4 min. Standard curve was prepared using different concentrations $(100-1000 \mu \mathrm{mol} / \mathrm{L})$ of $\mathrm{FeSO}_{4} \cdot 7 \mathrm{H}_{2} \mathrm{O}$. The antioxidant capacity based on the ability to reduce ferric ions of the extract was expressed as $\mathrm{mmol} \mathrm{Fe}^{2+} / \mathrm{L}$. All determinations were performed in triplicate.

\subsection{Statistical analysis}

Data presented are given as means \pm standard deviation (SD). Statistical significance was examined through one-way analysis of variance and Duncan's multiple range tests.
Significant differences were accepted at $p \leq 0.05$. Statistical processing data was performed using the Statistical Analysis System-SAS (Software version 8.1; SAS Institute, Inc.: Cary, NC, USA, 2000).

\section{Results and discussion}

\subsection{Proximate composition and mineral contents of the seed and leaves of Egyptian leek}

The proximate compositions of leek seeds and leaves are shown in Table 1. Moisture contents of leaves and seeds were 87.75 and $8.30 \%$, respectively. The seeds are good source of fat, protein, whereas the leaves are good source of crude fiber and ash. The seeds contain relatively high amounts of protein $19.50 \pm 1.85 \%$ and crude fat $14.90 \pm 2.35 \%$ and low fiber $9.50 \pm 1.01 \%$. The leaves contain a high amount of crude fiber $(23.82 \pm 2.57 \%)$, and ash $(15.90 \pm 1.62 \%)$ as well as low levels of protein and fat $8.50 \pm 1.65 \%$ and $6.50 \pm 1.18 \%$, respectively. Both seeds and leaves contain high amounts of carbohydrates 46.26 and $45.28 \%$, respectively. Available literature on composition of leek leaves show that the leaves contain 13.57$29.10 \%$ of protein, $2.80-14.40 \%$ of lipids, $39.9-43.9 \%$ of carbohydrates, $29.0-16.2 \%$ of ash and $23.57 \%$ of dietary fiber $[28,29]$. These differences can be attributed to soil, climate, strain, variety and agronomic practices. Green leafy vegetables are good source of minerals. Table 2 shows the mineral content of leek seeds and leaves. Ash content indicates that leek leaves is an appreciable source of minerals. Potassium is predominant element in the seeds and leaves 1040.09 and $1045.58 \mathrm{mg} / 100 \mathrm{~g}$ DW basis, respectively. Potassium, calcium, sodium, phosphorus and magnesium constituted the major minerals in leek leaves 1450.58, 1200.13, 490.00350 .85 and 220.10 $\mathrm{mg} / 100 \mathrm{~g}$ DW basis, respectively. The seeds contain moderate amounts of potassium, calcium, sodium, phosphorus and magnesium 1040.09, 910.32, 370.11, 240.61 and 160.42 $\mathrm{mg} / 100 \mathrm{~g}$ DW basis, respectively. Both seeds and leaves contain low levels of iron, copper; zinc and manganese. Generally, leaves had higher $(p<0.05)$ levels of mineral elements than seeds. Mineral content of leek leaves was higher than those reported by Athar et al. [28] for leek. These findings are in agreement with those obtained by Latif and Abd El-aal [29] except for potassium value which was lower.

Table 1. Proximate composition of seed and leaves of Egyptian leek per 100 g (dry weight basis).

\begin{tabular}{llll}
\hline Component & Seeds $\mathbf{a , d}$ & Leaves $^{\mathbf{a}, \mathbf{d}}$ & LSD \\
\hline Moisture & $8.30 \pm 1.03$ & $87.75 \pm 5.40$ & 8.812 \\
Crude protein $\mathrm{b}$ & $19.50 \pm 1.85$ & $8.50 \pm 1.65$ & 3.973 \\
Crude oil & $14.90 \pm 2.35$ & $6.50 \pm 1.18$ & 4.215 \\
Crude fiber & $9.50 \pm 1.01$ & $23.82 \pm 2.57$ & 4.426 \\
Ash & $9.84 \pm 0.85$ & $15.90 \pm 1.62$ & 2.932 \\
Total carbohydrate $\mathrm{c}$ & $46.26 \pm 6.12$ & $45.28 \pm 7.06$ & 14.97 \\
\hline
\end{tabular}

a $p \leq 0.05$.

b Crude protein $=\mathrm{N}(\%) \times 6.25$.

c Carbohydrate content obtained by subtracting the sum of moisture, crude protein, oil, crude fibre and ash from $100 \%$.

$\mathrm{d}$ Data are expressed as mean \pm SD.

e LSD: Least different significantly at $p \leq 0.05$ according to Duncan's multiple range test.

\subsection{Preliminary phytochemical screening}

Table 3 shows the qualitative data for the presence of different phytochemicals in leaves and seeds of Egyptian leek. Preliminary phytochemical revealed the presence of alkaloids, steroid, terpenoid, flavonoid, tannins, saponine, reducing sugar, proteins and oil in methanolic and ethanolic extracts of seeds and leaves of Egyptian leek. Alkaloids compounds were detected in all extracts of seeds and leaves, except the hexane extracts. Plants that possess alkaloids are pharmacologically active [30] as they have physiological effects on man and other animals and serve as therapeutic and antimalarial drugs. 
Table 2. Mineral contents of seeds and leaves of Egyptian leek (mg/100 g dry weight basis).

\begin{tabular}{|c|c|c|c|}
\hline Element & Seeds ${ }^{a, b}$ & Leaves $\mathrm{a}, \mathrm{b}$ & $L^{L S D}{ }^{c}$ \\
\hline \multicolumn{4}{|c|}{ Macro-elements } \\
\hline Potassium & $1040.09 \pm 22.12$ & $1045.58 \pm 13.60$ & 41.62 \\
\hline Phosphorus & $240.61 \pm 10.16$ & $350.85 \pm 20.10$ & 36.10 \\
\hline Magnesium & $160.42 \pm 12.25$ & $220.10 \pm 28.00$ & 48.99 \\
\hline Calcium & $910.32 \pm 14.50$ & $1200.13 \pm 41.02$ & 69.74 \\
\hline Sodium & $370.11 \pm 6.03$ & $490.00 \pm 3.05$ & 10.83 \\
\hline \multicolumn{4}{|c|}{ Micro-elements } \\
\hline Iron & $46.05 \pm 3.15$ & $60.51 \pm 6.21$ & 8.81 \\
\hline Copper & $0.95 \pm 0.10$ & $1.40 \pm 0.26$ & 0.34 \\
\hline Zinc & $4.75 \pm 0.11$ & $6.40 \pm 0.36$ & 0.45 \\
\hline Manganese & $10.9 \pm 0.18$ & $13.72 \pm 0.12$ & 0.32 \\
\hline
\end{tabular}

Table 3. Qualitative phytochemical analysis of seeds and leaves extracts of Egyptian leek in different solvent system *.

\begin{tabular}{|c|c|c|c|c|c|c|c|}
\hline \multirow[t]{2}{*}{ Chemical name } & \multirow[t]{2}{*}{ Part } & \multicolumn{6}{|l|}{ Extracts } \\
\hline & & Petroleum ether & Chloroform & Hexane & Methanol & Ethanol & Water \\
\hline \multirow[t]{2}{*}{ Alkaloids } & Seed & + & + & - & ++ & ++ & ++ \\
\hline & Leaf & + & + & - & ++ & ++ & ++ \\
\hline \multirow[t]{2}{*}{ Steroid } & Seed & + & - & - & ++ & + & - \\
\hline & Leaf & + & - & - & ++ & + & - \\
\hline \multirow[t]{2}{*}{ Terpenoid } & Seed & - & - & - & +++ & + & + \\
\hline & Leaf & - & - & - & +++ & + & + \\
\hline \multirow[t]{2}{*}{ Flavonoid } & Seed & - & ++ & - & +++ & ++ & ++ \\
\hline & Leaf & - & ++ & - & +++ & ++ & ++ \\
\hline \multirow[t]{2}{*}{ Tannins } & Seed & - & + & - & ++ & + & + \\
\hline & Leaf & - & + & - & ++ & + & + \\
\hline \multirow[t]{2}{*}{ Saponine } & Seed & - & - & - & + & + & + \\
\hline & Leaf & +++ & - & + & + & + & + \\
\hline \multirow[t]{2}{*}{ Reducing Sugar } & Seed & - & - & - & + & + & ++ \\
\hline & Leaf & - & - & - & + & + & ++ \\
\hline \multirow{2}{*}{ Proteins \& Amino Acids } & Seed & - & - & - & + & + & ++ \\
\hline & Leaf & - & - & - & + & + & t+ \\
\hline \multirow{2}{*}{ Fats \& Fixed Oils } & Seed & +++ & +++ & + & ++ & ++ & - \\
\hline & Leaf & +++ & +++ & + & ++ & ++ & - \\
\hline
\end{tabular}

$*_{+,++}$and +++ Refer to less presence, moderate presence and high presence of phytochemicals respectively; whereas - refers to the absence of phytochemicals.

These phytochemicals are known to perform several general and specific functions in plants, and may exhibit different biochemical and pharmacological actions in different species of animals when ingested. These actions range from cell toxicity to cell protective effects [1]. Terpenoid, flavonoid, tannins, reducing sugar and protein were not detected in petroleum ether and hexane extracts of seeds and leaves. Water extracts of seeds and leaves contain all tested phytochemicals except steroids and oils. Results indicated that the recovery of phytochemicals depends very much on the type and polarity of solvent used. Methanol and ethanol were the best solvent for extraction of these components. Meanwhile, petroleum ether, chloroform and hexane seemed to have the lowest extraction power among all the solvent systems used for extraction process. These findings may due to the ability of methanol and ethanol to penetrate the cellular membrane to extract the intracellular ingredients from the plant material [31].

\subsection{Extraction yields of antioxidant components from leaves and seeds of Egyptian leek}

Table 4 shows the extraction yields of antioxidant components obtained from seeds and leaves of Egyptian leek using various solvents. The yield of antioxidant components ranged from 1.55-13.95 g/100 g for leaves and 3.75-23.54 $\mathrm{g} / 100 \mathrm{~g}$ for seeds. Methanolic and ethanolic extracts of seeds had significantly $(p<0.05)$ the highest values of yield 23.54 and $18.95 \%$, respectively. Similarly, the methanolic and ethanolic extracts of leaves showed high values of yield 13.95 and $11.24 \%$, respectively. The lowest values of extraction yield were recorded for petroleum ether, chloroform and hexane extracts from both leaves and seeds. The amount of the antioxidant components that can be extracted from a plant material is mainly affected by the power of the extraction procedure, which may probably vary from sample to sample.
Amongst other contributing factors, efficiency of the extracting solvent to dissolve endogenous compounds might also be very important [31].

\subsection{Total phenolic, flavonoid and tannin contents of seeds and leaves extracts of Egyptian leek in different solvent system}

In this study, the determination of total phenolic content was done by the Folin Ciocalteu method which was introduced by Jayaprakasha et al. [22]. Phenolic compounds (PCs) may contribute directly to the antioxidant action; therefore, it is necessary to investigate total phenolic content. The seeds and leaves of Egyptian leek had total PCs in the range of 145.20$961.50 \mathrm{mg}$ gallic acid equivalents (GAE) per $100 \mathrm{~g}$ DW. As shown in Table 4, in all extracts, the contents of phenolics were higher in the seeds than in the leaves. The distribution of phenolic compounds in Egyptian leek illustrated that the methanolic extracts from both seeds and leaves contained highest amounts, 961.50 and $925.66 \mathrm{mg}$ gallic acid equivalents (GAE) per $100 \mathrm{~g} \mathrm{DW}$, respectively, followed by the phenolic compounds values of ethanolic (942.59 and 910.25) and water (725.80 and $710.11 \mathrm{mg}$ (GAE) / $100 \mathrm{~g} \mathrm{DW}$ ) extracts of seeds and leaves, respectively. On the contrary, the lowest levels of phenolics were estimated in petroleum ether, chloroform and hexane extracts from both leaves and seeds. Flavonoids possess a broad spectrum of biological activities including antioxidant and radical scavenging properties [32], therefore the total flavonoid contents in the extracts were determined (Table 4), in terms of mg catechin equivalents (CE) / $100 \mathrm{~g}$. The total flavonoid contents of the seeds and leaves of Egyptian leek varied in the different extracts and ranged from 54.00 to $382.20 \mathrm{mg}$ catechin equivalents (CE) / $100 \mathrm{~g}$. Leek leaves had significantly higher total flavonoid content than the seeds. Formation of flavonoids has been shown to be light dependent. 
Table 4. Total phenolic, flavonoid and tannin contents and Percentage yield of seeds and leaves extracts of Egyptian leek in different solvent system.

\begin{tabular}{|c|c|c|c|c|c|c|c|c|}
\hline \multirow[t]{2}{*}{ Extract } & \multicolumn{2}{|c|}{ Total polyphenols $\mathrm{a}, \mathrm{b}, \mathrm{c}$} & \multicolumn{2}{|l|}{ Flavonoids ${ }^{a, b, d}$} & \multicolumn{2}{|l|}{ Tannins $\mathrm{a}, \mathrm{b}, \mathrm{e}$} & \multicolumn{2}{|l|}{ Yield, \% ${ }^{a, b}$} \\
\hline & Seeds & Leaves & Seeds & Leaves & Seeds & Leaves & Seeds & Leaves \\
\hline Methanol & $961.50 \pm 36.08$ & $925.66 \pm 45.21$ & $280.40 \pm 12.01$ & $382.20 \pm 44.60$ & $112.66 \pm 10.47$ & $110.30 \pm 9.22$ & $23.54 \pm 1.88$ & $13.95 \pm 1.93$ \\
\hline Ethanol & $942.59 \pm 45.19$ & $910.25 \pm 26.58$ & $268.90 \pm 14.13$ & $371.00 \pm 26.17$ & $103.65 \pm 11.14$ & $104.24 \pm 8.16$ & $18.95 \pm 1.72$ & $11.24 \pm 1.04$ \\
\hline Water & $725.80 \pm 19.33$ & $710.11 \pm 26.88$ & $259.00 \pm 6.98$ & $314.00 \pm 22.50$ & $88.54 \pm 9.81$ & $90.00 \pm 7.14$ & $9.41 \pm 1.32$ & $5.58 \pm 0.54$ \\
\hline Petroleum ether & $270.55 \pm 14.26$ & $255.30 \pm 18.10$ & $59.11 \pm 8.33$ & $60.56 \pm 9.07$ & $46.21 \pm 4.99$ & $35.50 \pm 3.89$ & $3.75 \pm 0.14$ & $1.55 \pm 0.20$ \\
\hline Chloroform & $420.10 \pm 62.30$ & $402.50 \pm 50.47$ & $206.02 \pm 11.56$ & $268.70 \pm 16.22$ & $69.50 \pm 8.04$ & $65.33 \pm 5.81$ & $4.91 \pm 0.13$ & $1.99 \pm 0.10$ \\
\hline Hexane & $162.24 \pm 17.19$ & $145.20 \pm 8.69$ & $54.00 \pm 5.81$ & $59.45 \pm 7.82$ & $35.13 \pm 6.18$ & $30.22 \pm 5.42$ & $4.33 \pm 0.36$ & $2.01 \pm 0.17$ \\
\hline LSD at 0.05 & 58.671 & & 31.618 & & 13.159 & & 2.277 & \\
\hline
\end{tabular}

a $p \leq 0.05$.

b Data are expressed as mean \pm SD.

c Total polyphenols are expressed as mg gallic acid/100 g of dry plant material.

d Flavonoids are expressed as mg catechin/100 g of dry plant material.

e Tannin is expressed as mg tannic acid/100 g of dry plant material.

Table 5. DPPH radical scavenging capacity, antioxidant activity (as \%, $\beta$-carotene bleaching) and ferric reducing antioxidant power, FRAP (mmol Fe ${ }^{2+} / \mathrm{L}$ ) of Egyptian leek (Allium ampeloprasum var. kurrat) extracts.

\begin{tabular}{|c|c|c|c|c|c|c|}
\hline \multirow[t]{2}{*}{ Extract } & \multicolumn{2}{|c|}{ DPPH radical scavenging (\%) } & \multicolumn{2}{|c|}{$\begin{array}{l}\text { Antioxidant activity (\%) } \\
\beta \text {-carotene bleaching }\end{array}$} & \multicolumn{2}{|c|}{$\begin{array}{l}\text { Antioxidant activity (FRAP) } \\
\left(\mathrm{mmol} \mathrm{Fe}^{2+} / \mathrm{L}\right)\end{array}$} \\
\hline & Seeds $\mathbf{a}, \mathbf{b}$ & Leaves ${ }^{a, b}$ & Seeds ${ }^{a, b}$ & Leaves $a, b$ & Seeds ${ }^{a, b}$ & Leaves ${ }^{a, b}$ \\
\hline Methanol & $74.13 \pm 3.74$ & $86.61 \pm 2.92$ & $86.71 \pm 2.97$ & $91.85 \pm 3.85$ & $35.38 \pm 1.16$ & $33.76 \pm 1.12$ \\
\hline Ethanol & $70.54 \pm 2.95$ & $83.43 \pm 2.87$ & $81.00 \pm 4.10$ & $87.24 \pm 3.78$ & $33.16 \pm 1.84$ & $33.05 \pm 1.44$ \\
\hline Water & $45.85 \pm 2.26$ & $47.17 \pm 1.45$ & $56.00 \pm 5.47$ & $61.13 \pm 2.52$ & $22.70 \pm 1.29$ & $24.66 \pm 1.36$ \\
\hline Petroleum ether & $24.14 \pm 2.21$ & $33.90 \pm 1.23$ & $41.00 \pm 3.45$ & $36.19 \pm 1.44$ & $6.23 \pm 0.85$ & $5.74 \pm 0.45$ \\
\hline Chloroform & $37.12 \pm 2.35$ & $38.00 \pm 1.46$ & $46.44 \pm 3.19$ & $46.98 \pm 2.48$ & $6.48 \pm 0.92$ & $6.80 \pm 0.84$ \\
\hline Hexane & $25.10 \pm 1.86$ & $30.24 \pm 1.02$ & $42.50 \pm 1.73$ & $35.12 \pm 1.63$ & $8.71 \pm 1.01$ & $7.25 \pm 0.61$ \\
\hline LSD c & 3.928 & & 5.481 & & 1.960 & \\
\hline
\end{tabular}

a $p \leq 0.05$.

$\mathrm{b}$ Data are expressed as mean $\pm \mathrm{SD}$

c LSD: Least different significantly at $p \leq 0.05$ according to Duncan's multiple range test.

In addition, higher amounts of flavonoids may be required in the leaf for protection against environmental stresses [33]. Methanolic and ethanolic extracts of leaves had significantly the highest $(p<0.05)$ levels of flavonoid 382.20 and $371.00 \mathrm{mg}$ catechin equivalents (CE) / $100 \mathrm{~g}$, respectively. Similarly, the methanolic and ethanolic extracts of seeds showed moderate levels of flavonoids 280.40 and $268.90 \mathrm{mg} / 100 \mathrm{~g}$, respectively. Table 4 depicts also that, the seeds and leaves of Egyptian leek had tannins in the range of 30.22-112.66 mg tannic acid per $100 \mathrm{~g}$ DW. Methanolic extracts of the seeds and leaves had significantly $(p<0.05)$ the greatest levels of tannins 112.66 and $110.30 \mathrm{mg}$ tannic acid per $100 \mathrm{~g}$ DW, while the least $(p<0.05)$ levels of tannins were shown by petroleum ether and hexane extracts of both seeds and leaves. This observation was similar to the result reported by Antolovich et al. [6] who reported that solubility of phenolic compounds is governed by the type of solvent (polarity) used, degree of polymerization of phenolics, as well as interaction of phenolics with other food constituents and formation of insoluble complexes. Therefore, there is no uniform or completely satisfactory procedure that is suitable for extraction of all phenolics or a specific class of phenolic substances in plant materials. Methanol, ethanol, acetone, water, ethyl acetate and their combinations are frequently used for the extraction of phenolics.

\subsection{DPPH radical scavenging and total antioxidant activities of Egyptian leek extracts}

Antioxidant capacity, as determined by DPPH radical scavenging activity, $\beta$-carotene bleaching and ferric reducing antioxidant power (FRAP) assays, is shown in Table 5. DPPH is a free radical that easily accepts an electron or hydrogen radical to become a stable diamagnetic molecule; DPPH scavenging can be measured in vitro or in vivo by EPH spectroscopy [34]. It can accommodate a large number of samples within a short period, and is sensitive enough to detect low concentrations of the active principles [35]. The DPPH radical-scavenging activity expressed in \% inhibition of the seeds and leaves extracts ranged from 24.14 to $86.61 \%$. The methanolic and ethanolic extracts of leaves had significantly the higher DPPH radical-scavenging activity 86.61 and $83.43 \%$, respectively, followed by the methanolic and ethanolic extracts of seeds 74.13 and $70.54 \%$, respectively. The radicalscavenging activities of these extracts can be attributed to the presence of some compounds that have antioxidant activity. The higher content of total phenolic compounds, the stronger antioxidant activity [36]. However, petroleum ether and hexane extracts of seeds showed significantly $(p<0.05)$ the lowest values of DPPH radical scavenging activity 24.14 and $25.10 \%$, respectively. The $\beta$-carotene bleaching method (coupled oxidation of $\beta$ - carotene and linoleic acid) estimates the relative ability of antioxidant compounds in the plant extracts to scavenge the radical of linoleic acid peroxide that oxidizes $\beta$ carotene in the emulsion phase [37]. Total antioxidant activity of the seeds and leaves extracts as measured by the bleaching of beta-carotene ranged from 35.12 to $91.85 \%$. Methanolic and ethanolic extracts of leaves had significantly $(p<0.05)$ the highest antioxidant activity 91.85 and $87.24 \%$, respectively, followed by methanolic extract of seeds $(86.71 \%)$, ethanolic extract of seeds $(81.00 \%)$ and aqueous extract of seeds and leaves (61.13 and $56.00 \%)$, respectively. While the lowest antioxidant activities were shown by petroleum ether and hexane extracts of seeds ( 41.00 and $42.50 \%$ ) and leaves (36.19 and $35.12 \%$ ), respectively. The higher antioxidant activity of methanolic and ethanolic extracts than of petroleum ether and hexane extracts may be due to the presence of higher concentrations of both phenolics and flavonoids (Table 4). In previous works, flavonoids and phenolics have been reported as potent antioxidants in $\beta$-carotene-linoleic acid bleaching systems [37]. FRAP assay measures the change in absorbance at $593 \mathrm{~nm}$ owing to the formation of a blue colored $\mathrm{Fe}^{2+}$ tripyridyltriazine compound from colorless oxidized $\mathrm{Fe}^{3+}$ form by the action of electron donating antioxidants. The antioxidant capacity as measured by FRAP of both seeds and leaves extracts ranged from 5.74 to $35.38 \mathrm{mM} / \mathrm{L}$. Methanolic and ethanolic extracts had significantly $(p<0.05)$ the highest values of antioxidant capacity (33.05- $35.38 \mathrm{mmol} \mathrm{Fe}{ }^{2+} / \mathrm{L}$ of extract). However, petroleum ether, chloroform and hexane extracts showed significantly $(p<0.05)$ the lowest values of antioxidant capacity (5.74-8.71 mmol $\mathrm{Fe}^{2+} / \mathrm{L}$ of extract). The trend for ferric reducing antioxidant activities of seeds and leaves of Egyptian leek extracts did not vary markedly from their DPPH free radical scavenging activities. It may be concluded from the DPPH, $\beta$-carotene bleaching and FRAP assays that methanolic 
and ethanolic extracts of seeds and leaves of Egyptian leek (Allium ampeloprasum var. kurrat) have high levels of antioxidants.

\subsection{HPLC analysis of phenolic compounds in methanolic extract of the seeds and leaves of Egyptian leek}

According to the results (Tables 4 and 5), methanolic extracts of the seeds and leaves possessed the highest values of total phenolic, flavonoid, tannin, radical scavenging and antioxidant activity, therefore, phenolic profiles of methanolic extracts of the seeds and leaves of Egyptian leek were determined by using HPLC (High-Performance Liquid Chromatography) method. Results indicate that certain phenolic compounds; gallic, coumaric, caffeic, tannic, vanillic and chlorogenic acid, rutin and quercetin exist in methanolic extracts of both seeds and leaves at different levels (Table 6). These compounds have been identified according to their retention time and the spectral characteristics of their peaks compared to those of standards, as well as by spiking the sample with standards. The quantities of the identified compounds are expressed in mg per $100 \mathrm{~g}$ of dry plant material. Chlorogenic acid was detected to be the major phenolic component in methanolic extracts of seeds and leaves 322 and $302 \mathrm{mg} / 100 \mathrm{~g}$, these levels represent 33.48 and $32.62 \%$ of total phenolic compounds of seeds and leaves, respectively. Chlorogenic acid (3-caffeoylquinic acid) is one of the most common soluble phenolic derivatives. The ability of many plant tissues to accumulate this phenolic ester is so great that chlorogenic acid, like lignin, would appear to be an endproduct of phenolic biosynthesis [38]. Methanolic extract of leaves had significantly the highest $(p<0.05)$ levels of quercetin and rutin 194.50 and $61.00 \mathrm{mg} / 100 \mathrm{~g}$, respectively. Seeds also had relatively good amounts of these flavonoids 70.91 and $32.00 \mathrm{mg} / 100 \mathrm{~g}$, respectively. Flavonoids are generally present in plants bound to sugar as glycosides and any one flavonoid aglycone may occur in a single plant in several glycosidic combinations. Flavonoids widely present in vegetables, are potent antioxidants [32]. Moderate levels of gallic, coumaric, caffeic, tannic and vanillic acids were shown for methanolic extract of seeds $(46.51,44.32,33.60,26.41$ and 29.30) and leaves (39.45, 41.21, 34.58, 23.56 and $27.12 \mathrm{mg} /$ $100 \mathrm{~g}$ ), respectively. It was reported that a number of phenolic compounds including gallic acid, ellagic acid, caffeic, tannic, vanillic, chlorogenic, rutin and quercetin showed high antioxidant activities [39]; therefore, medicinal plant extracts consisting of high amounts of these compounds could act as a potent natural antioxidant.

Table 6. HPLC analysis of phenolic compounds (mg / $100 \mathrm{~g} \mathrm{DW}$ ) in the methanolic extract of Egyptian leek seed.

\begin{tabular}{lll} 
Phenolic compound & \multicolumn{2}{l}{ Methanolic extract } \\
& Seeds & Leaves \\
\hline Gallic & 46.51 & 39.45 \\
Coumaric & 44.32 & 41.21 \\
Caffeic & 33.60 & 34.58 \\
Tannic & 26.41 & 23.56 \\
Vanillic & 29.30 & 27.12 \\
Chlorogenic & 322.00 & 302.00 \\
Kaempferol & 70.91 & 194.50 \\
Quercetin & 32.00 & 61.00 \\
\hline
\end{tabular}

\section{Conclusions}

It is concluded that methanolic and ethanolic extracts of the seeds and leaves of Egyptian leek (Allium ampeloprasum var. kurrat) have substantial amounts of phenolic compounds. Presence of these phenolics in seeds and leaves extracts might be responsible for DPPH radical scavenging activity, betacarotene bleaching and reducing antioxidant power. This indicated that methanolic and ethanolic extracts of seeds and leaves of Egyptian leek (Allium ampeloprasum var. kurrat) contained potential antioxidant bioactive compounds, and may serve as alternative source of natural antioxidant for nutraceutical and functional food applications.

\section{References}

[1]. Velioglu, Y. S.; Mazza, G.; Gao, L.; Oomah, B. D. J. Agric. Food Chem 1998, 46(10), 4113-4117.

[2]. Prior, R. L.; Cao, G. Hort. Sci. 2000, 35(49), 588-592.

[3]. Robinson, D. S. Food Biochemistry and Nutritional Value. Longman Scientific and Technical Publisher, New York, USA 1990.

[4]. Sasaki, Y.; Kawaguchi, S.; Kamaya, A.; Ohshita, M.; Kabasawa, K. Iwama, K.; Taniguchi, K.; Tsuda, S. Mutat. Res. Gen. Tox. En. 2002, 519, 103-119.

[5]. Chang, S. B.; Yang, T. J.; Datema, E.; Van Vugt, J.; Vosman, B.; Kuipers, A.; Meznikova, M.; Szinay, D.; Klein, R.; Lankhorst, E.; Jacobsen, H.; de Jong. Chromosome Res. 2008, 16, 919-933.

[6]. Antolovich, M.; Prenzler, P.; Robards, K.; Ryan, D. Analyst 2000, 125 989-1009.

[7]. Sultana, B.; Anwar, F.; Ashraf, M. Molecules, 2009, 14(6), 2167-2180

[8]. Peschel, W.; Sanchez-Rabaneda, F.; Dn, W.; Plescher, A.; Gartzia, I.; Jimenez, D.; Lamuela- Raventos, R.; Buxaderas, S.; Condina, C. Food Chem. 2006, 97(1), 137-150.

[9]. Fujita, Y. T.; Tanaka, M.; Kuwata, K.; Okuzumi, J.; Takahashi, T.; Fujiki, H.; Okuda, T. Jpn. J. Cancer Res. 1989, 80, 503-505.

[10]. Malairajan, P.; Geetha, G.; Narasimhan, S.; Jessi, K. J. Ethnopharmacol. 2006, 106(3), 425-428

[11]. Lanzotti, V. J. Chromatogr. A, 2006, 1112(1-2), 3-22.

[12]. Hsing, A. W.; Chokkalingam, A. P.; Gao, Y. T.; Madigan, M. P.; Deng, J.; Gridley, G.; Fraumeni, J. F. J. Natl. Cancer Inst. 2002, 94, 1648-1651.

[13]. Galeone, C.; Pelucchi, C.; Levi, F.; Negri, E.; Fraceschi, S.; Talamini, R.; Giacosa, A.; La Vecchia, C. Am. J. Clin. Nutr. 2006, 84, 1027-1032.

[14]. Yin, M. C.; Tsao, S. M. Int. J. Food Microbi. 1999, 49(1-2), 49-56.

[15]. Fattorusso, E.; Lanzotti, V.; Taglialatela-Scafati, O.; Cicala, C. Phytochemistry 2001, 57(4), 565-569.

[16]. Jones, H. A.; Mann, L. K. London, Leonard Hill, 1963.

[17]. Yamaguchi, M. World vegetables, AVI Book, Van Nostrand Reinhold, New York, 1983.

[18]. Kadry, A. R.; Kamel, S. A. Sven. Bot. Tidskr. 1955, 49, 314-324.

[19]. Currah, L. J. Hortic. Soc. 1986, 61, 407-415.

[20]. AOAC $17^{\text {th }}$ edn. (Edited by W Horwitz), Washington, DC 2000.

[21]. Trease, G. E.; Evans, I. C. $12^{\text {th }}$ Edn. Bailliere Tindall, London, 1983, pp. 21-22.

[22]. Ayaprakasha, G.; Selvi, T.; Sakariah, K. Food Res. Int. 2003, 36(2), 117 122.

[23]. Meda, A.; Lamien, C. E.; Romito, M.; Millogo, J.; Nacoulma, O. G. Food Chem. 2005, 91(3), 571-577.

[24]. Polshettiwar, S. A.; Ganjiwale, R. O.; Wadher, S. J.; Yeole, P. G. Indian J. Pharm. Sci. 2007, 69(4), 574-576.

[25]. Wu, J. W.; Hsieh, C. L.; Wang, H.; Chen, H. Y. Food Chem. 2009, 113(1), 78-84.

[26]. Juntachote, T.; Berghofer, E. Food Chem. 2005, 92(2), 193-202.

[27]. Xu, B. J.; Chang, S. K. C. J. Food Sci. 2007, 72, S159-S166.

[28]. Athar, N.; Taylor, G.; McLaughlin, J.; Skinner, J. Food files 2004. In, New Zealand Institute for Crop \& Food Research Limited and New Zealand Ministry of Health 2004.

[29]. Latif , S. S.; Abd El-Aal, H. A. African Crop Sci. Conf. Proceed. 2007, 8, 1817-1826.

[30]. Ruhland, W. The metabolism of secondary products, Springer-Verlay, Berlin, 1958.

[31]. Sultana, B.; Anwar, F.; Przybylski, R. Food Chem. 2007, 104(3), 11061114.

[32]. Galvez, M.; Martin-Cordero, C.; Houghton, P. J.; Ayuso, M. J. J. Agr. Food Chem. 2005, 53, 1927-1933.

[33]. Jaakola, L.; Maatta-Riihinen, K.; Karenlampi, S.; Hohtola, A. Planta 2004, 218(3), 721-728.

[34]. Fuchs, J.; Weber, S.; Podda, M.; Groth, N.; Herrling, T.; Packer, L.; Kaufmann, R. Free Radic. Biol. Med. 2003, 34, 330-336.

[35]. Yokozawa, T.; Chen, C. P.; Dong, E.; Tanaka, T.; Nonaka, G. I.; Nishioka, I. Biochem. Pharmacol. 1998, 56(2), 213-222.

[36]. Baardseth, P.; Bjerke, F.; Martinsen, B. K.; Skrede, G. J. Sci. Food Agric. 2010, 90(7), 1245-1255.

[37]. Schwarz, K.; Huang, S. W.; German, J. B.; Tiersch, B.; Hartmann, J.; Frankel, E. N. J. Agr. Food Chem. 2000, 48, 4874-4882.

[38]. Zucker, M.; Nitsch, C.; Nitsch, J. P. Am. J. Bot. 1965, 52(3), 271-277.

[39]. Iacopini, P.; Bald, M.; Storchi, P.; Sebastiani, L. J. Food Compos. Anal. 2008, 21(8), 589-598. 